\title{
Incorporation of Amphipathic Diblock Copolymer in Lipid Bilayer for Improving pH Responsiveness
}

\author{
Tian Xia, Weiju Hao, Yazhuo Shang, Shouhong Xu, and Honglai Liu \\ Key Laboratory for Advanced Materials and Department of Chemistry, East China University of Science and Technology, \\ Shanghai 200237, China
}

Correspondence should be addressed to Shouhong Xu; xushouhong@ecust.edu.cn

Received 3 February 2016; Accepted 10 April 2016

Academic Editor: Yohei Kotsuchibashi

Copyright (C) 2016 Tian Xia et al. This is an open access article distributed under the Creative Commons Attribution License, which permits unrestricted use, distribution, and reproduction in any medium, provided the original work is properly cited.

Diblock copolymers (mPEG-b-PDPA), which were designed to possess pH-sensitivity as well as amphipathy, were used as an intelligent lock in the liposomal membrane. The so-called $\mathrm{pH}$-sensitive liposomes were prepared by simple mixing of the synthesized mPEG-b-PDPA with phospholipids and cholesterol. Fluorescence polarization at pH 7.4 showed that the membrane stability of the hybrid liposome was significantly increased compared with the pure liposome. Therefore, in the neutral environment, the leakage of doxorubicin (DOX) was inhibited. However, when $\mathrm{pH}$ decreased to 6.0, DOX release rate increased by $60 \%$ due to the escape of copolymer. The effects of the membrane composition and the PDPA segment length on bilayer membrane functions were investigated. These results revealed that the synthesized copolymers increased the difference in DOX cumulative release between $\mathrm{pH} 7.4$ and 6.0, that is, improved the $\mathrm{pH}$-controllability of the drug release from hybrid liposomes.

\section{Introduction}

There exists a long-term problem that is how to improve the switch effect of drug carriers for the sake of preventing the drug leakage during transport before reaching to the target sites and stimulating the release of drugs at the appropriate time $[1,2]$. It is very important to design a kind of intelligent carrier for delivering drugs to the target site accurately and releasing drugs timely in a certain environment with the help of the environmental stimulation. In recent years, researchers have prepared $\mathrm{pH}$-sensitive [3-5], thermosensitive [6-8], and photosensitive $[9,10]$ vesicle for drug delivery system, in response to the various physiological and pathological environments.

For example, triblock copolymers poly(N-vinylcaprolactam)-poly(dimethylsiloxane)-poly(N-vinylcaprolactam) (PVCL-PDMS-PVCL) with temperature sensitivity were synthesized and used to deliver anticancer drugs in physiological temperature range of $37-42^{\circ} \mathrm{C}$ [11]. Benzoyl peroxide (BPO) had been incorporated into a $\mathrm{pH}$-sensitive mesoporous silica nanocomposite and the enhanced free radical generation induced higher cytotoxicity at $\mathrm{pH} 6.5$ than $\mathrm{pH} 7.4$ [12]. Many $\mathrm{pH}$-responsive copolymers had been designed and synthesized for various applications $[13,14]$. For example, Arg-Gly-Asp-polycarboxybetaine methacrylate-poly(2-(diisopropylamino)ethyl methacrylate) (RGD-PCB-PDPA) triblock copolymers were prepared by Huang and coworkers. Their in vitro and in vivo evaluation findings showed that the multifunctional RGD-PCB-PDPA nanoparticle was a flexible design approach, which indicated a great potential for nanocarriers in tumor-targeted drug delivery.

We are interested in designing and preparing liposomes with various stimuli responsibilities. Liposome has attracted much attention in the field of medicine as a drug carrier. Liposome, known as a phospholipid-based vesicle, is composed of a closed vesicle with a structure of bilayer constructed by self-assembly in the aqueous phase $[15,16]$. We have synthesized a series $\mathrm{pH}$-sensitive di- and triblock copolymers and inserted it into liposome for $\mathrm{pH}$-controlled releasing [17]. In general, the drug release mechanism of $\mathrm{pH}$ sensitive nanocarriers is often based on the $\mathrm{pH}$-triggered protonation, or hydrolysis, or dissolution/degradation of the polymers $[18,19]$. The $\mathrm{pH}$ values of extracellular matrix of tumor site, endosome, and lysosome are known to be in weak acid. Then, poly(2-(diisopropylamino) methyl methacrylate) 
(PDPA), whose triggered $\mathrm{pH}$ value (about 6.2) is appropriate for physiological environment, was often selected to be the $\mathrm{pH}$-sensitive segment for various materials $[20,21]$.

We believe a diblock $\mathrm{pH}$-sensitive copolymer might give "lock" effect on lipid membrane fluidity and just need to adjust the block size. In this paper, we synthesized $\mathrm{pH}$ sensitive diblock copolymers with various PDPA lengths. In order to make the diblock copolymers act as a lock, the PDPA lengths were selected to be similar to the thickness of phospholipid bilayer. The synthesized diblock copolymers were inserted into liposome membrane, which was composed of hydrogenated soybean phosphatidylcholine (HSPC), 1,2-dioleoyl-sn-3-phosphocholine (DOPC) [22] and DC-cholesterol. DC-cholesterol was selected for providing positive charge to liposomes so that the liposomes could keep from aggregating. The synthesized polymer is positively charged under neutral environment. At $\mathrm{pH} 7.4$, the interaction between DC-cholesterol and polymer should be electroattraction, while at $\mathrm{pH} 6.0$, the protonated polymers become hydrophilic and escaped from liposomes. The electrorepulsion between PDPA blocks and liposomes should help the escaping behavior. Then, the release behaviors of these hybrid liposomes were comparatively studied under $\mathrm{pH}$ 7.4 and $\mathrm{pH}$ 6.0. This study confirmed that the DOX-loaded liposome containing $\mathrm{pH}$-responsive diblock copolymers was able to inhibit drug release at $\mathrm{pH} 7.4$ and gave a motivation to release drug at $\mathrm{pH}$ 6.0. The synthesized copolymer played a very good role to improve the biofunction of lipid bilayer.

\section{Experimental}

2.1. Materials. Methoxypolyethylene glycol (mPEG350), 2-(diisopropylamino) ethyl methacrylate (DPA, 97\%), and copper(I) bromide $(\mathrm{CuBr} ; 99.99 \%)$ were purchased from Sigma-Aldrich. 1,6-Diphenyl-1,3,5-hexatriene (DPH), doxorubicin hydrochloride (DOX. $\mathrm{HCl}, 98 \%)$ and 2-bromo2-methylpropionyl bromide (98\%) were obtained from J\&K Scientific. N,N, $\mathrm{N}^{\prime}, \mathrm{N}^{\prime}, \mathrm{N}^{\prime}$-Pentamethydieyhylenetriamine (PMDETA, 98\%) was provided by TCI. Tetrahydrofuran (anhydrous) (THF, AR) and trichloromethane (AR) were bought from Tianlian Company. Aluminium oxide used for removal of the ATRP copper catalyst was of column chromatography grades 100-200 list order from Tianlian Company. 1-Palmitoyl-2-stearoyl-sn-glycero-3-phosphatidylcholine (HSPC > 98\%), 1,2-dioleoyl-sn-glycero-3-phosphocholine (DOPC > 97\%), and DC-cholesterol were provided from Lipoid.

\subsection{Characterizations}

2.2.1. Proton Nuclear Magnetic Resonance ( ${ }^{1} H$ NMR) and Gel Permeation Chromatography (GPC) Characterization. Molecular weight and polydispersity index (PDI) of mPEGb-PDPA copolymers were determined by gel permeation chromatography (GPC) using a Waters 1515 instrument at $25^{\circ} \mathrm{C}$. THF was used as an eluent with a flow rate of $1.0 \mathrm{~mL} / \mathrm{min}$ and polystyrene was used as calibration standard. A Bruker $500 \mathrm{MHz}$ NMR spectrometer instrument was used to acquire the ${ }^{1} \mathrm{H}$ NMR spectra of $\mathrm{mPEG}-\mathrm{Br}$ and mPEG-b-PDPA using $\mathrm{CDCl}_{3}$ as solvent. The block copolymer compositions were determined by comparing appropriate integrals assigned to the different comonomers.

2.2.2. Transmission Electron Microscopy (TEM). Transmission Electron Microscopy (TEM) images were performed on a JEM-1400 electron microscope operated at $100 \mathrm{kv}$. To prepare TEM samples, the liposome suspension was deposited on a carbon-coated copper grid and negatively stained with the phosphotungstic acid solution. Excess solution was absorbed and the samples were allowed to dry at ambient temperature.

2.2.3. Dynamic Light Scattering (DLS). Dynamic light scattering (DLS) studies were carried out using a Zetasizer Nano ZS Instrument. The influence of $\mathrm{pH}$ on zeta-potential of liposomes was investigated in the range of $\mathrm{pH} 2-9[17,20]$. The diblock copolymers were firstly dissolved in $0.01 \mathrm{M} \mathrm{HCl}$ to prepare stock solution at final a concentration of $0.1 \mathrm{mg} / \mathrm{mL}$. The $\mathrm{pH}$ titration was carried out by adding small volume of $0.1 \mathrm{M} \mathrm{NaOH}$ solution under stirring. The change of $\mathrm{pH}$ values was monitored by using PHS-2C precision acidity meter. The average results were accepted as the final data measured at least three times.

2.2.4. Turbidity. The aggregation behavior of the copolymer was measured in a UV-Vis spectrophotometer (UV-2450, Shimadzu, Japan). The transmittance of the copolymer solution was monitored in a quartz cuvette $(1 \mathrm{~cm}$ width) under various $\mathrm{pH}$ values.

2.2.5. Fluorescence Polarization. The fluorescence polarization (Pol) of liposome was measured by a LS55 fluorimeter (Perkin Elmer) equipped with automated polarizer. Liposome suspensions were prepared: $75 \mu \mathrm{L}$ of liposome suspension and $200 \mu \mathrm{L}$ of DPH solution were added to the PBS buffer solution to be further diluted to $4 \mathrm{~mL}$. The concentration of DPH was $2 \mathrm{mmol} / \mathrm{L}$ and lipid/DPH (w/w) was $800: 1$. In order to make the probes to be incorporated, the samples were shaken overnight at $37^{\circ} \mathrm{C}$ before measurements. The Pol values were measured at an excitation slit of $10 \mathrm{~nm}$ and emission slit of $5 \mathrm{~nm}$ and excitation and emission wavelengths of 360 and $425 \mathrm{~nm}$, respectively. Fluorescence polarization was then calculated automatically by $[23,24]$

$$
\text { Pol }=\frac{\left(I_{v v}-G I_{v h}\right)}{\left(I_{v v}+G I_{v h}\right)},
$$

where Pol is the fluorescence polarization and $I_{v v}$ and $I_{v h}$ are the fluorescence intensities of the emitted light polarized parallel and perpendicular to the exciting light, respectively. $G$ is the grating correction factor, which is equal to $I_{h v} / I_{h h}$, obtained by measuring the vertically and horizontally polarized emission intensities after excitation with horizontally polarized light.

2.3. Synthesis of mPEG-Br Macroinitiator. mPEG-Br macroinitiator was synthesized according to the literature method $[21,25]$. Typically, mPEG-OH $(0.0086 \mathrm{~mol})$ was dropped 
TABLE 1: GPC, ${ }^{1} \mathrm{H}$ NMR, and triggering $\mathrm{pH}$ values of mPEG-b-PDPA diblock copolymers.

\begin{tabular}{lccccc}
\hline Copolymer & Composition & $M_{n, \mathrm{NMR}}\left(\mathrm{gmol}^{-1}\right)$ & $M_{n, \mathrm{GPC}}\left(\mathrm{gmol}^{-1}\right)$ & PDI $\left(M_{w} / M_{n}\right)$ & 1.37 \\
$\mathbf{1}$ & $\mathrm{mPEG}_{8}-\mathrm{b}-\mathrm{PDPA}_{10}$ & 2632 & 4171 & 1.22 & 6.36 \\
$\mathbf{2}$ & $\mathrm{mPEG}_{8}-\mathrm{b}-\mathrm{PDPA}_{15}$ & 3699 & 4037 & 7.47 \\
$\mathbf{3}$ & $\mathrm{mPEG}_{8}-\mathrm{b}-\mathrm{PDPA}_{22}$ & 5192 & 7227 & 1.19 \\
\hline
\end{tabular}

into $50 \mathrm{~mL}$ of dichloromethane. The flask containing the solution was placed in an ice bath, and trimethylamine (TEA) $(0.0216 \mathrm{~mol})$ was added to the solution. Then, 2-bromo-2methylpropionyl bromide $(0.0202 \mathrm{~mol})$ was added dropwise to the solution over $1 \mathrm{~h}$ under stirring and then the reaction was continued for about $30 \mathrm{~h}$ at room temperature. The crude solution was washed with saturated sodium chloride solution and saturated sodium hydrogen carbonate solution for three times followed by extracting with dichloromethane. After that, anhydrous magnesium sulfate was added to the extract liquor and then filtered to remove insoluble impurities and concentrated by evaporation. The product was finally dried under vacuum for about $12 \mathrm{~h}$.

2.4. Synthesis of mPEG-b-PDPA Diblock Copolymer. The diblock copolymer was synthesized by ATRP with mPEG$\mathrm{Br}$ as initiator [26, 27]. In a typical ATRP procedure, a Schlenk flask with a magnetic stir bar and a rubber septum was charged with DPA monomer (12.657 mmol), mPEGBr macroinitiator $(0.8438 \mathrm{mmol})$, PMDETA $(0.9282 \mathrm{mmol})$, and anhydrous tetrahydrofuran $(6.0 \mathrm{~mL})$. This mixture was deoxygenated by bubbling $\mathrm{N}_{2}$ for $0.5 \mathrm{~h}$ before adding $\mathrm{Cu}^{\mathrm{I}} \mathrm{Br}$ catalyst $(0.8438 \mathrm{mmol})$. The reactant mixture was degassed by three freezing-thawing cycles. Afterwards, the polymerization reaction was carried out in an oil bath preheated at $55^{\circ} \mathrm{C}$ for $12 \mathrm{~h}$. Finally, the reaction solution was diluted by addition of THF and then passed through a neutral alumina column to remove the copper catalysts. The diblock copolymer was then washed by Milli-Q water for at least 3 times and dried under vacuum for $24 \mathrm{~h}$.

2.5. Preparation of Liposomes. Liposomes were prepared by a thin lipid film hydration method [28]. In brief, HSPC or DOPC, DC-cholesterol, and different mole ratio of diblock copolymer were dissolved in chloroform in a round bottom flask. Then a film was formed by rotary evaporation of the solvent at the temperature of $45^{\circ} \mathrm{C}$ and then organic solvent was volatilized completely after $1 \mathrm{~h}$. The lipid film was hydrated with $5 \mathrm{~mL}$ of ammonium sulfate solution at $60^{\circ} \mathrm{C}$ to achieve a final lipid concentration of $1 \mathrm{mg} / \mathrm{mL}$. Following hydration, uniform liposomes were obtained by extrusion at $60^{\circ} \mathrm{C}$ through $400 \mathrm{~nm}$ polycarbonate filter 11 times and then $200 \mathrm{~nm}$ filter 7 times by using a LiposoFast.

2.6. Drug Loading. The active transport method was used to encapsulate DOX into liposome. The liposome suspension was dialyzed against the $0.9 \% \mathrm{NaCl}$ solution using dialysis tubes (cutoff $M_{n}=14000$ ) to remove the free ammonium sulfate acid. Then, the suspension was placed in a flask. DOX solution $(2.5 \mathrm{mg} / \mathrm{mL})$ was mixed with the liposome suspension at the molar ratio of 1:10 (DOX:lipids). The unloaded free DOX was removed through a Sephadex G-50 column. The liposomes loaded with DOX were collected and mixed with Triton X-100 for measuring encapsulated amount. The total DOX amount $A_{1}$ and encapsulated DOX amount $A_{0}$ were determined by the absorbing intensity at $485 \mathrm{~nm}$ (UV-2450, Shimadzu). The encapsulated efficiency (E\%) was calculated based on [29]

$$
E \%=\frac{A_{0}}{A_{1}} \times 100 \% .
$$

2.7. In Vitro DOX Release. In vitro DOX release was carried under various $\mathrm{pH}$ values ( $\mathrm{pH} 6.0$ or 7.4). $1 \mathrm{~mL}$ of DOX-loaded liposome suspension was moved to a dialysis tube (cutoff $M n=14000$ ), which was exposed to $25 \mathrm{~mL}$ of PBS solution at $37^{\circ} \mathrm{C}$. The cumulative release amount of DOX at different time $A_{t}$ was measured and the release percentage was calculated:

$$
\text { Cumulative release } \%=\frac{A_{t}}{A_{0}} \times 100 \% \text {. }
$$

\section{Results and Discussions}

3.1. Synthesis of $m P E G-P D P A$. The mPEG-b-PDPA diblock copolymers with different block lengths were synthesized [30]. Considering the thickness of the lipid bilayer, not very long chains were selected for PDPA ( $n=10,15$, and 22). The properties of the copolymers, determined by GPC and ${ }^{1} \mathrm{H}$ NMR, were shown in Table 1 and Figure 1. These diblock copolymers had a small polydispersity index (PDI), showing that the distributions of mPEG-b-PDPA were narrow, uniform, and well controlled. Various degrees of polymerization of the copolymers can be obtained by changing the feed ratio of raw materials. GPC curves (not shown) revealed that unimodal peak and no tailing in the low molecular weight were observed. ${ }^{1} \mathrm{H}$ NMR spectra of $\mathrm{mPEG}-\mathrm{Br}$ and $\mathrm{mPEG}-$ b-PDPA with the relevant peaks were illustrated in Figure 1. As shown in Figure $1(\mathrm{~A})$, the peaks at $\delta 3.60$ and $\delta 3.33 \mathrm{ppm}$ were assigned to protons of $-\mathrm{CH}_{2}-\mathrm{CH}_{2}$ and $-\mathrm{OCH}_{3}$ groups of the $\mathrm{mPEG}-\mathrm{Br}$, respectively. The peak at $\delta 1.96 \mathrm{ppm}$ belonged to $-\mathrm{C}\left(\mathrm{CH}_{3}\right)_{2}$ - groups. Compared with the ${ }^{1} \mathrm{H}$ NMR spectrum of mPEG-Br (Figure 1(A)), the characteristic peaks at $\delta 0.97$ and $\delta 2.60 \mathrm{ppm}$ appeared in the spectrum of mPEG-b-PDPA (Figure 1(B)), which were assigned to - $\mathrm{CH}-\left(\mathrm{CH}_{3}\right)_{2}$ - and $\mathrm{O}-\mathrm{CH}_{2}-\mathrm{CH}_{2}-\mathrm{N}$ - groups, indicating the presence of PDPA. According to these results, the copolymers of the desired structures were successfully synthesized.

3.2. $p H$-Sensitivity of mPEG-b-PDPA Diblock Copolymers. The diblock copolymers responded to the change of 
TABLE 2: Compositions and properties of the liposomes (pH 7.4).

\begin{tabular}{|c|c|c|c|c|c|}
\hline Liposome & Composition of liposome $\mathrm{a}^{\mathrm{a}}$ & Copolymer percentage & Diameter $(\mathrm{nm})$ & PDI & Zeta-potential $(\mathrm{mV})$ \\
\hline Lp1 & HSPC & 0 & $139.3 \pm 4.0$ & 0.151 & $10.3 \pm 0.8$ \\
\hline Lp2 & $\begin{array}{c}\text { HSPC : polymer } \\
\left(\mathrm{mPEG}_{8}-\mathrm{b}-\mathrm{PDPA}_{10}\right)\end{array}$ & $5 \%$ & $173.2 \pm 8.0$ & 0.229 & $13.6 \pm 1.4$ \\
\hline Lp3 & $\begin{array}{c}\text { HSPC : polymer } \\
\left(\mathrm{mPEG}_{8}-\mathrm{b}-\mathrm{PDPA}_{15}\right)\end{array}$ & $5 \%$ & $183.7 \pm 8.0$ & 0.246 & $15.8 \pm 1.4$ \\
\hline Lp4 & $\begin{array}{c}\text { HSPC : polymer } \\
\left(\mathrm{mPEG}_{8}-\mathrm{b}-\mathrm{PDPA}_{22}\right)\end{array}$ & $2 \%$ & $179.9 \pm 8.0$ & 0.219 & $15.7 \pm 1.4$ \\
\hline Lp5 & $\begin{array}{c}\text { HSPC : polymer } \\
\left(\mathrm{mPEG}_{8}-\mathrm{b}-\mathrm{PDPA}_{22}\right)\end{array}$ & $5 \%$ & $198.8 \pm 8.0$ & 0.250 & $16.9 \pm 1.4$ \\
\hline Lp6 & $\begin{array}{c}\text { HSPC : polymer } \\
\left(\mathrm{mPEG}_{8}-\mathrm{b}-\mathrm{PDPA}_{22}\right)\end{array}$ & $10 \%$ & $206.2 \pm 8.0$ & 0.334 & $18.7 \pm 1.4$ \\
\hline Lp7 & HSPC : DOPC $(1: 1)$ & 0 & $146.0 \pm 4.0$ & 0.178 & $11.6 \pm 1.4$ \\
\hline Lp8 & 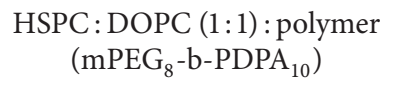 & $5 \%$ & $163.5 \pm 8.0$ & 0.207 & $17.2 \pm 1.4$ \\
\hline Lp9 & $\begin{array}{l}\text { HSPC : } \operatorname{DOPC}(1: 1): \text { polymer } \\
\quad\left(\mathrm{mPEG}_{8}-\mathrm{b}-\mathrm{PDPA}_{15}\right)\end{array}$ & $5 \%$ & $175.1 \pm 8.0$ & 0.210 & $16.1 \pm 1.4$ \\
\hline Lp10 & 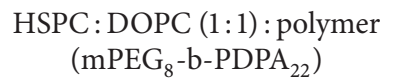 & $5 \%$ & $187.3 \pm 8.0$ & 0.207 & $17.2 \pm 1.4$ \\
\hline
\end{tabular}

${ }^{\mathrm{a}}$ Cholesterol was contained in all liposomes and the molar ratio between lipid and cholesterol was $5: 1$.

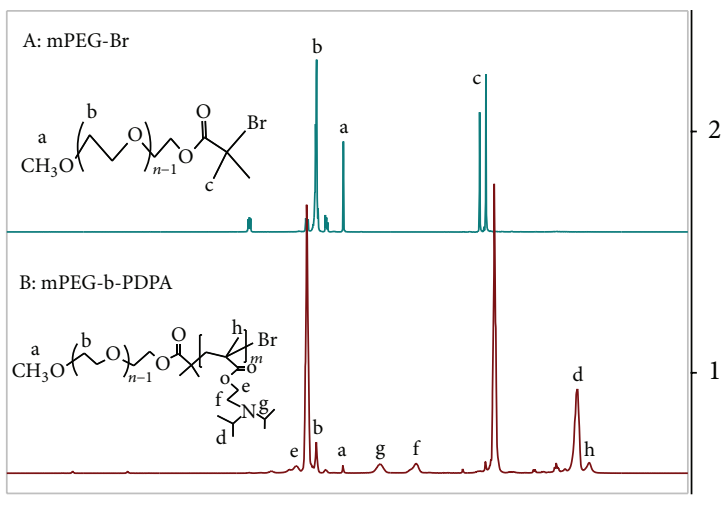

\begin{tabular}{llllllllllllllll}
\hline 6.5 & 6.0 & 5.5 & 5.0 & 4.5 & 4.0 & 3.5 & 3.0 & 2.5 & 2.0 & 1.5 & 1.0 & 0.5 & 0.0
\end{tabular} $f_{1}(\mathrm{ppm})$

FIGURE 1: ${ }^{1} \mathrm{H}$ NMR spectra $\left(\mathrm{CDCl}_{3}\right)$ of mPEG-Br $(\mathrm{A})$ and mPEG-bPDPA (B).

environmental $\mathrm{pH}$. In order to obtain a better understanding of the pH-sensitive mPEG-b-PDPA copolymers, the properties of copolymers in a certain $\mathrm{pH}$ range had been investigated. Figure 2(a) shows the zeta-potential of the copolymers under different $\mathrm{pH}$ values. At low $\mathrm{pH}$, the tertiary amine groups of PDPA block were protonated, which provided high positive zeta-potential. With increasing $\mathrm{pH}$, the tertiary amine groups of PDPA block were deprotonated gradually, which induced a transition in charges from positive to negative values. As shown in Figure 2(a), the isoelectric points (IEP) of these copolymers were in a range of $\mathrm{pH}$ 6.5-7.0. Thus, it clearly revealed that the property of the diblock copolymers was significantly affected by $\mathrm{pH}$ of the solution. The transmittances of copolymer solutions at different $\mathrm{pH}$ values were measured and shown in Figure 2(b).
The triggering $\mathrm{pH}$ values of the diblock copolymers, which could be determined at a certain $\mathrm{pH}$ value when the solution suddenly became turbid, were listed in Table 1 . It could be seen that the triggering $\mathrm{pH}$ values increased slightly with the increase of PDPA length. This might be due to the fact that more tertiary amine groups need to be deprotonated when the PDPA lengths increased.

3.3. The pH-Sensitivity of Hybrid Liposomes. The $\mathrm{pH}-$ sensitive hybrid liposomes were prepared by incorporating diblock copolymers into the liposome bilayer membranes with different molar ratios. The physicochemical properties of the liposomes were summarized in Table 2. In this work, the molar ratio between phospholipids and cholesterol was always $5: 1$.

As shown in Table 2, pH-sensitive hybrid liposomes appeared to be larger than the pure liposome (Lp1) under $\mathrm{pH}$ 7.4, which may be due to the stretching PEG chains from the bilayer. It could be seen that the sizes of Lp2, Lp3, and Lp5 were somewhat increased, which was thought to depend on the increase of PDPA lengths. The sizes of hybrid liposomes were found not to change when $\mathrm{pH}$ decreased from 7.4 to 6.0 as shown in Figure 3. Their zeta-potentials under $\mathrm{pH} 7.4$ were also shown in Table 2, which were found to be the same as their values under $\mathrm{pH}$ 6.0. The results revealed that the vesicle structures of hybrid liposomes were not destroyed by the stimulation of $\mathrm{pH}$, which should relate to their positive zeta-potentials and the PEG extending on the surface. The morphology of liposome was examined by TEM (Figure 2, inset). The TEM images showed round-shaped vesicles whose sizes were found consistent with the diameters obtained by DLS. TEM images also revealed that the vesicle structures of liposomes still exist when the condition changed from neutral to weak acid. 


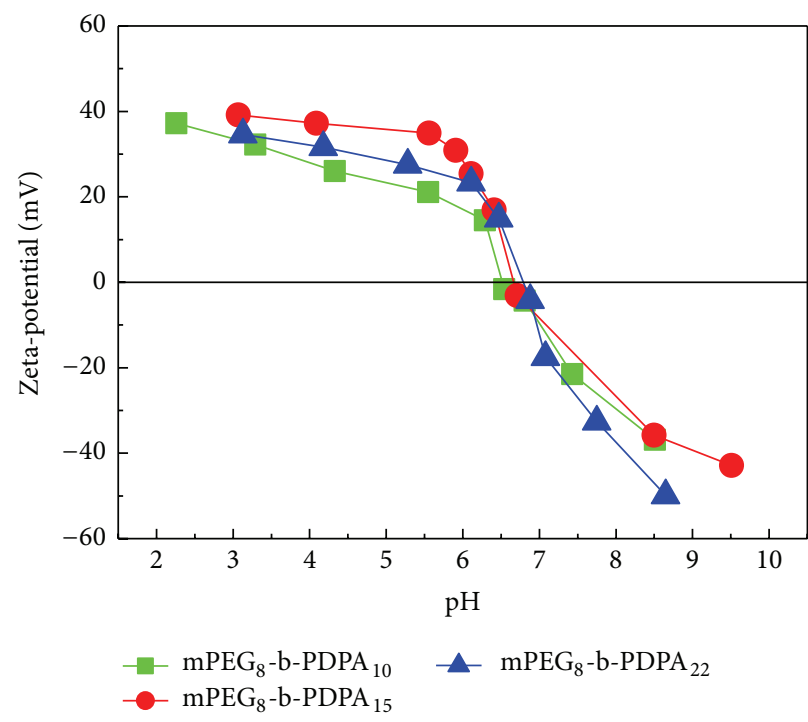

(a)

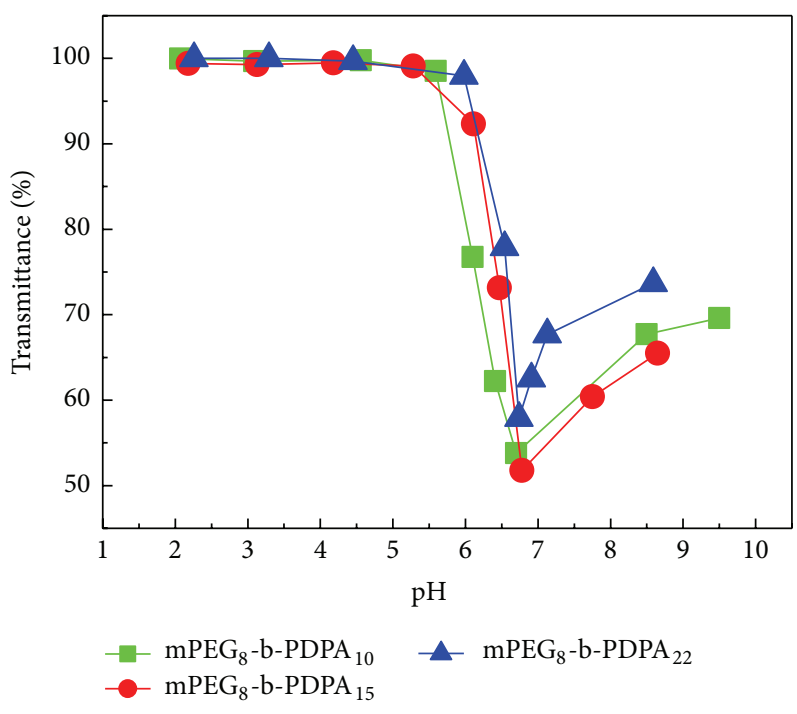

(b)

FIGURE 2: The pH-sensitivity of diblock copolymers. Zeta-potential (a) and transmittance (b) of copolymers measured as a function of pH (concentration of copolymer: $0.1 \mathrm{mg} / \mathrm{mL}$ ).

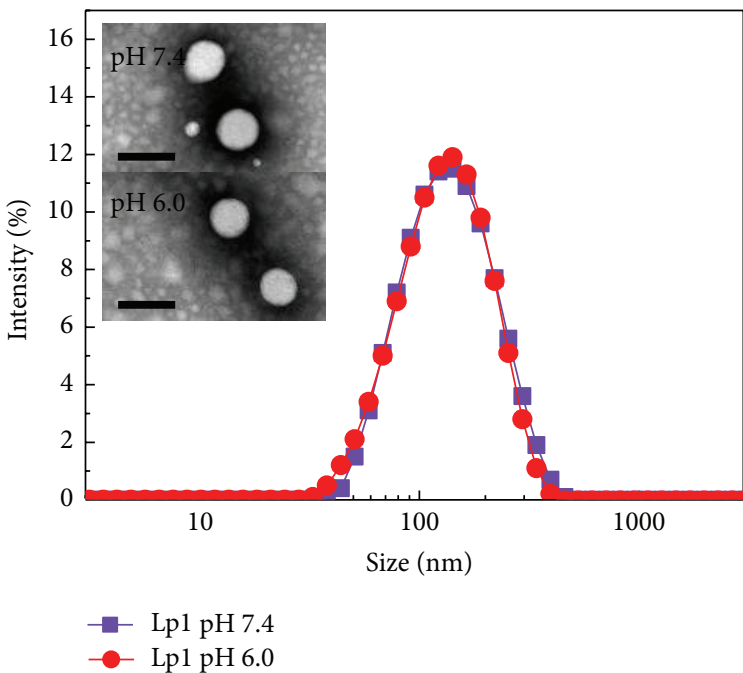

(a)

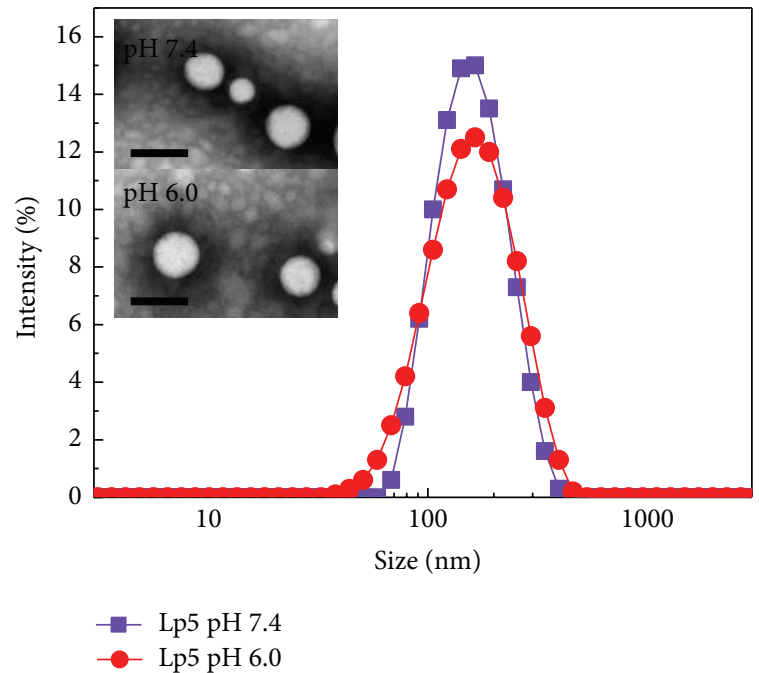

(b)

FIGURE 3: Size distributions and TEM images (inset, bar: $200 \mathrm{~nm}$ ) of Lpl (a) and Lp5 (b) under pH 6.0 and pH 7.4, separately. The concentration of the liposome suspension was $1.0 \mathrm{mg} / \mathrm{mL}$.

Then, Pol measurements were performed. DPH was used as a fluorescence probe to investigate the membrane fluidity of the liposomes [31,32]. The behavior of fluorescence probe in liposomal membranes was deemed to reflect the behavior of lipids. The lower the value of the Pol, the higher the fluidity (i.e., lower stability) of the liposomal membrane. The Pol values of the liposome bilayer membrane were found almost constant over time under $\mathrm{pH}$ 7.4. As shown in Figure 4(a), the Pol values increased obviously when $5 \%$ of diblock copolymers were incorporated (Lp3 and Lp5), compared with pure liposome (Lp1). Except for Lp2, its Pol value had a slight decrease, which may be due to the short length of PDPA chain. A shorter PDPA $\left(\mathrm{PDPA}_{10}\right)$ had a length similar to the thickness of liposomal single-layer. Therefore, copolymer $1\left(\mathrm{mPEG}_{8}-\mathrm{b}-\mathrm{PDPA}_{10}\right)$ could not reach the second layer of the liposome and could not act as a lock to fix the bilayer. The insertion of copolymer $\mathbf{1}$, on the contrary, led to a slight decrease in membrane stability. The Pol values of Lp3 and Lp5 significantly increased, suggesting that the copolymers with longer PDPA could go across the whole lipid bilayer and enhanced the membrane stability.

Figure 4(b) reveals the Pol values of various liposomes measured as a function of time under $\mathrm{pH}$ 6.0. For pure liposome (Lp1), when $\mathrm{pH}$ decreased from 7.4 to 6.0, the Pol 


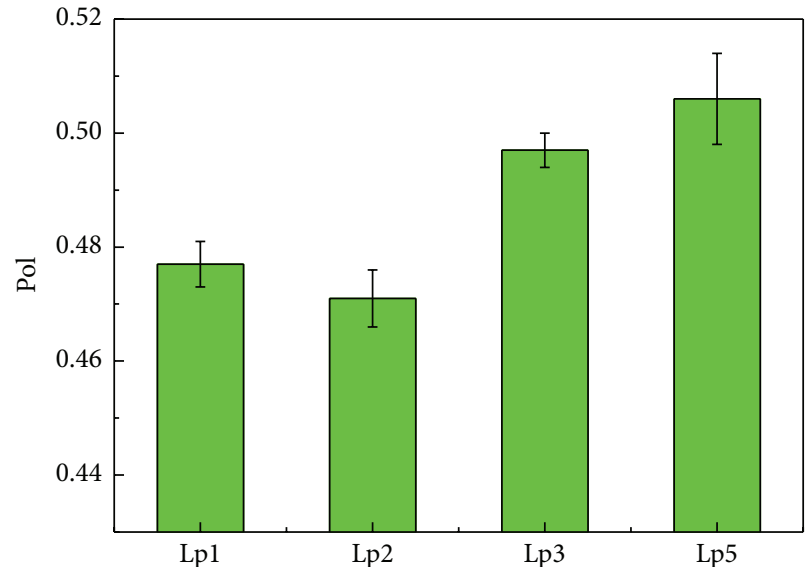

(a)

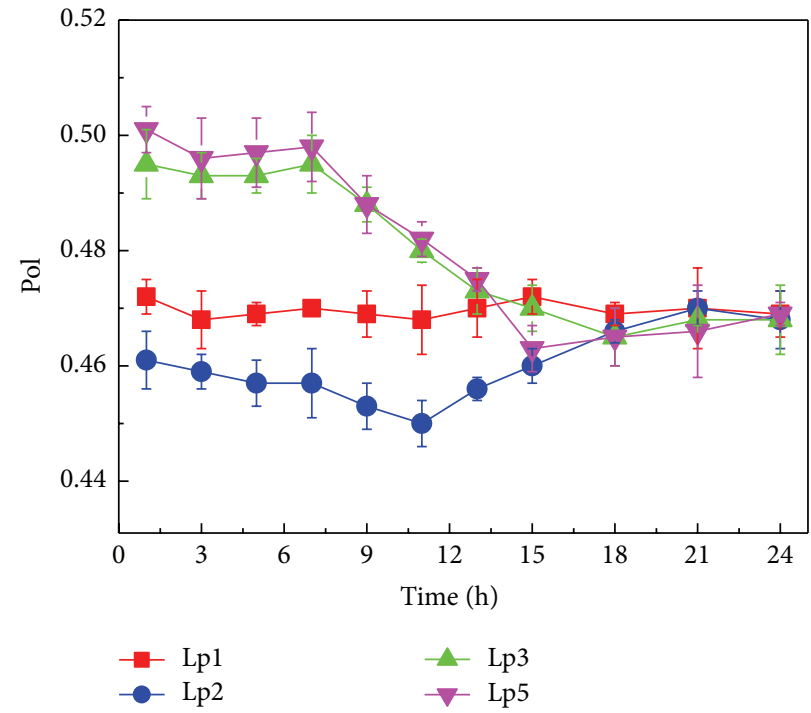

(b)

Figure 4: (a) Polarization of pure and hybrid liposomes at $\mathrm{pH} 7.4$; (b) polarization of liposomes at $\mathrm{pH} 6.0$ measured as a function of time. The molar ratio of copolymers was $5 \%$.

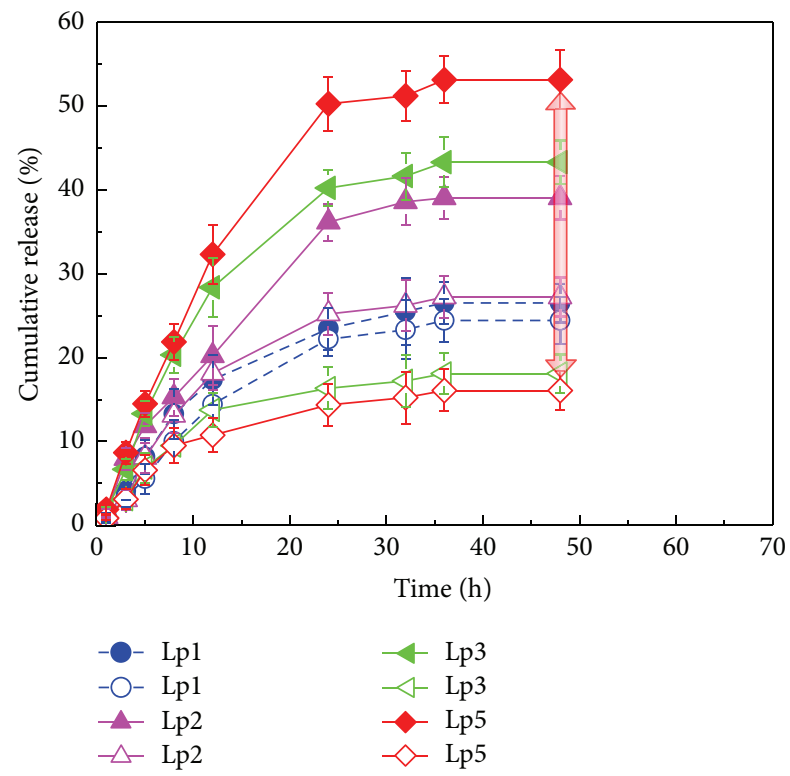

FIGURE 5: Cumulative release profiles of DOX from pure liposome and hybrid liposomes inserted by copolymers with different PDPA segment sizes. Solid symbol: $\mathrm{pH}$ 6.0. Open symbol: $\mathrm{pH}$ 7.4. The molar ratio of copolymers was $5 \%$.

values were found not to change over the whole time period, indicating $\mathrm{pH}$ did not affect its membrane fluidity. However, Pol values of Lp3 and Lp5 decreased obviously at pH 6.0. This was thought to result from the escape of the copolymers from liposomes. The copolymers became completely hydrophilic and then could not stay in the lipid bilayer when the PDPA block protonated. After about $18 \mathrm{~h}$, their Pol values became close to that of Lp1, suggesting a pure liposome state came back again. Certainly, the Pol value of Lp2 also tended to approach that of pure liposome.
3.4. Effect of PDPA Length on Release. In order to assess the drug loading and releasing of the liposomes, DOX was used as a model drug. DOX is a water-soluble anticancer drug in its hydrochloride salt form. Herein, DOX was encapsulated into liposomes using an active loading method and the drug loading efficiency was over $80 \%$. Experiment of DOX release from liposome was performed in PBS solution with different $\mathrm{pH}$ values $(\mathrm{pH} 6.0$ and $\mathrm{pH} 7.4)$ at $37^{\circ} \mathrm{C}$. Copolymers with different lengths had been synthesized in this work to study the effect of PDPA segment size on the release behavior. The compositions and properties of the corresponding liposomes (Lp2, Lp3, and Lp5) were summarized in Table 2. Their DOX release profiles were investigated and shown in Figure 5.

For the pure liposome, no significant differences (about $26.5 \%$ and $24.4 \%$ ) were observed in the drug release profiles under both $\mathrm{pH}$ values, suggesting that $\mathrm{pH}$ itself did not affect the membrane permeability. However, for liposomes incorporated with diblock copolymers, the drug release profiles showed different behaviors depending on $\mathrm{pH}$. Under $\mathrm{pH}$ 7.4, the drug release from the hybrid liposomes (except for Lp2) decreased to be $18.1 \%$ (Lp3) and $15.1 \%$ (Lp5) compared with that of Lpl, indicating that drug leakage was inhibited. And under $\mathrm{pH}$ 6.0, the drug releases of the three hybrid liposomes obviously increased, which were $39.1 \%$ (Lp2), 43.3\% (Lp3), and 53.2\% (Lp5). For Lp5, the difference in cumulative release percentage between the two $\mathrm{pH}$ values increased by about $40 \%$, which was most remarkable. The results highlighted that copolymers with proper length of PDPA played an important role, that is, acted as an intelligent lock in lipid bilayer to inhibit the drug leakage under neutral environment and enhance the release under weak acidic condition. The enhanced release occurring at $\mathrm{pH} 6.0$ was thought to result from the escaping of copolymers from the liposomes [17]. From the results of polarization (Figure 4), the PDPA block of copolymer was protonated gradually under $\mathrm{pH}$ 6.0. It could 


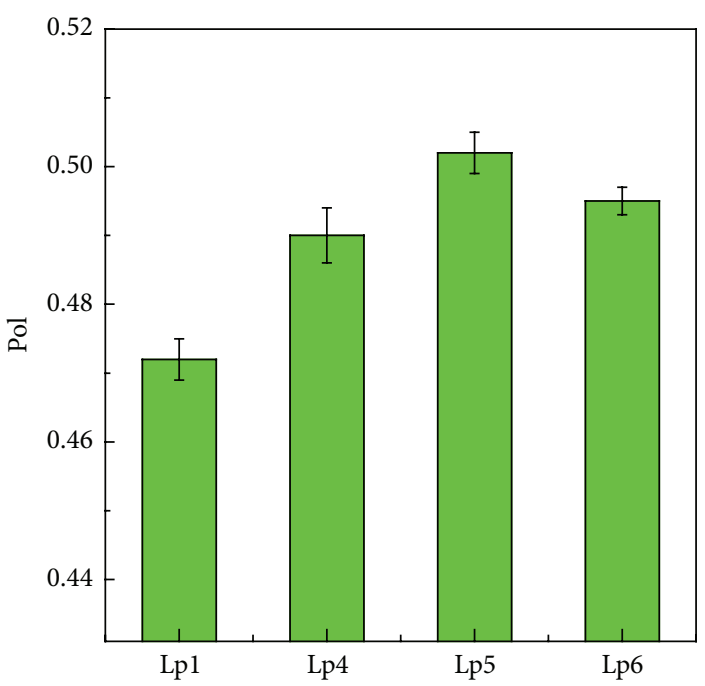

(a)
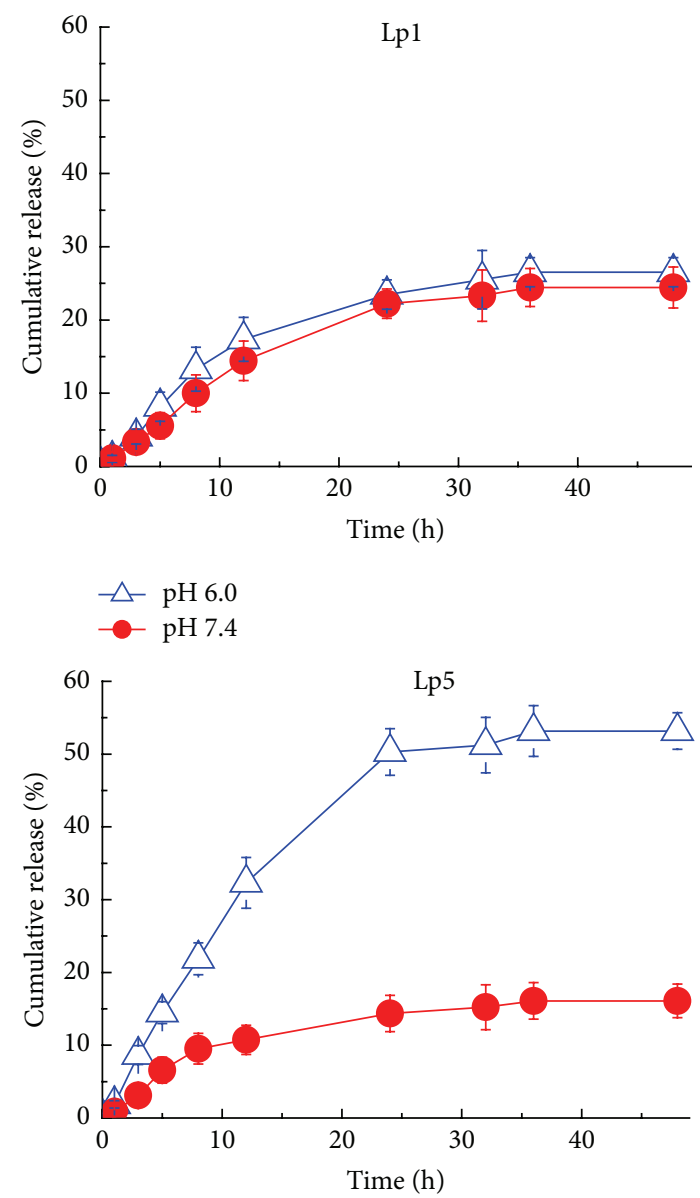

$-\mathrm{pH} 6.0$
$-\mathrm{pH} 7.4$

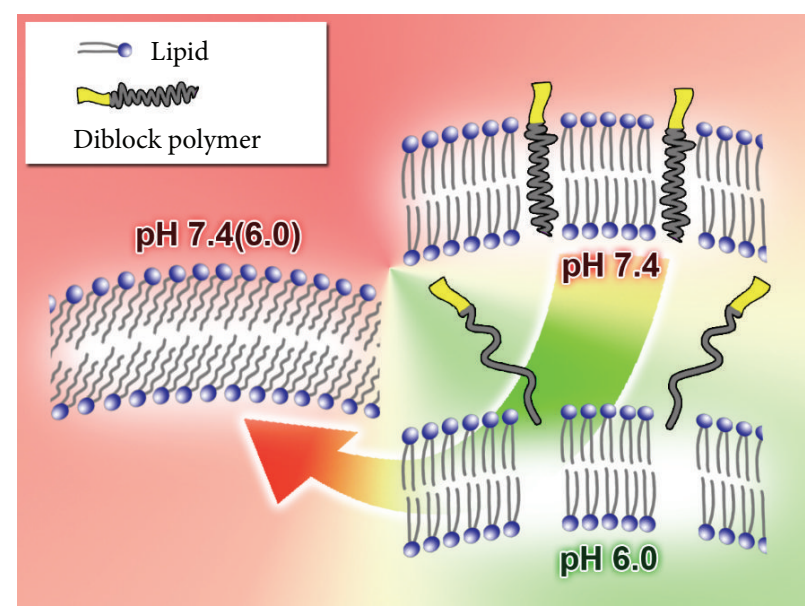

(b)

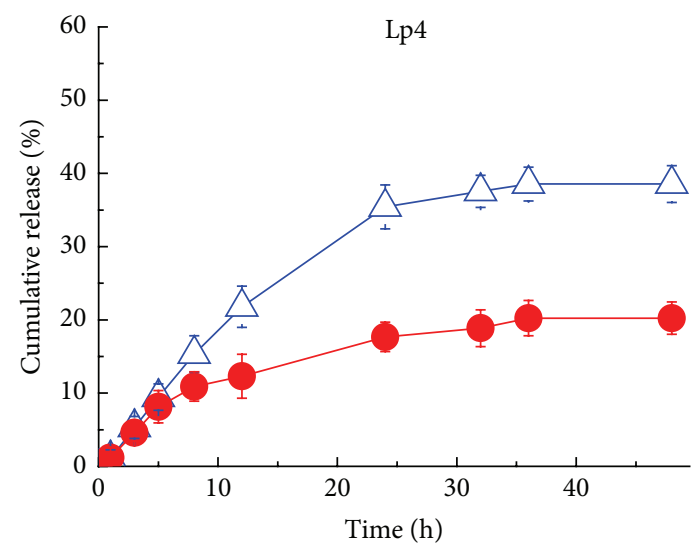

$\triangle \mathrm{pH} 6.0$

$-\mathrm{pH} 7.4$

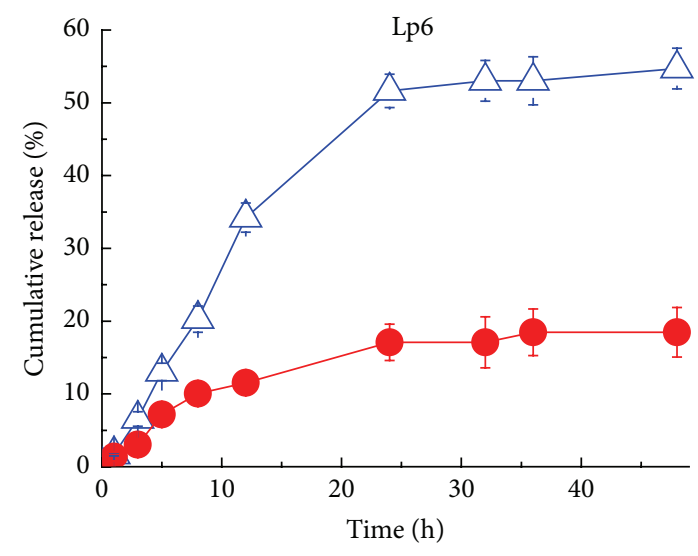

$-\triangle \mathrm{pH} 6.0$

$\rightarrow$ pH 7.4

(c)

FIgURE 6: (a) The Pol values of hybrid liposomes incorporated with various copolymer contents at pH 7.4 measured immediately after preparation; (b) scheme of copolymers inserting into lipid bilayer as locks; (c) cumulative release profiles of DOX from liposomes inserted by various ratios of $\mathrm{mPEG}_{8}-\mathrm{b}-\mathrm{PDPA}_{22}$ under $\mathrm{pH} 6.0$ and $\mathrm{pH} 7.4$ at $37^{\circ} \mathrm{C}$. 


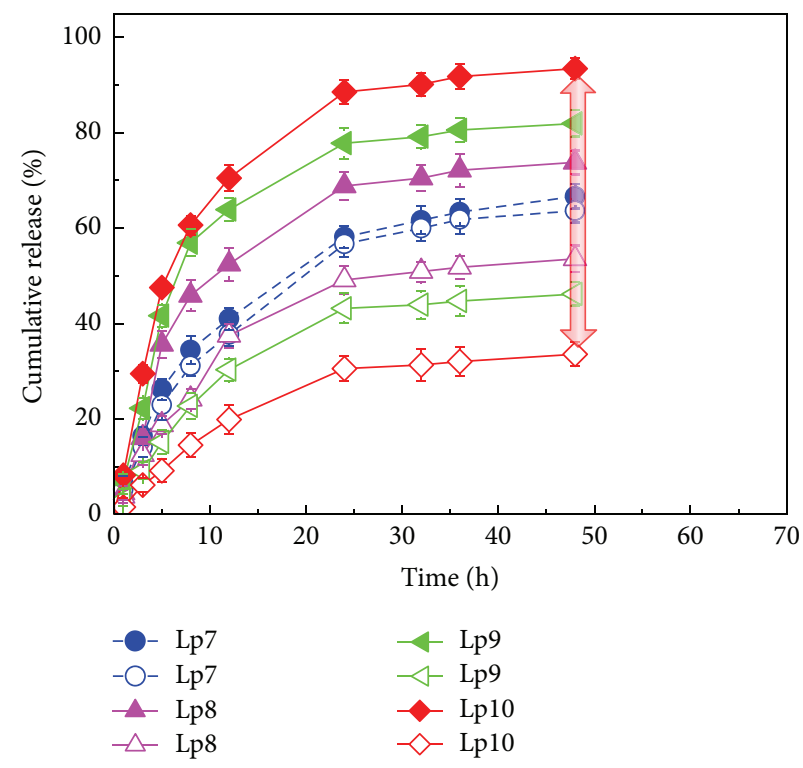

(a)

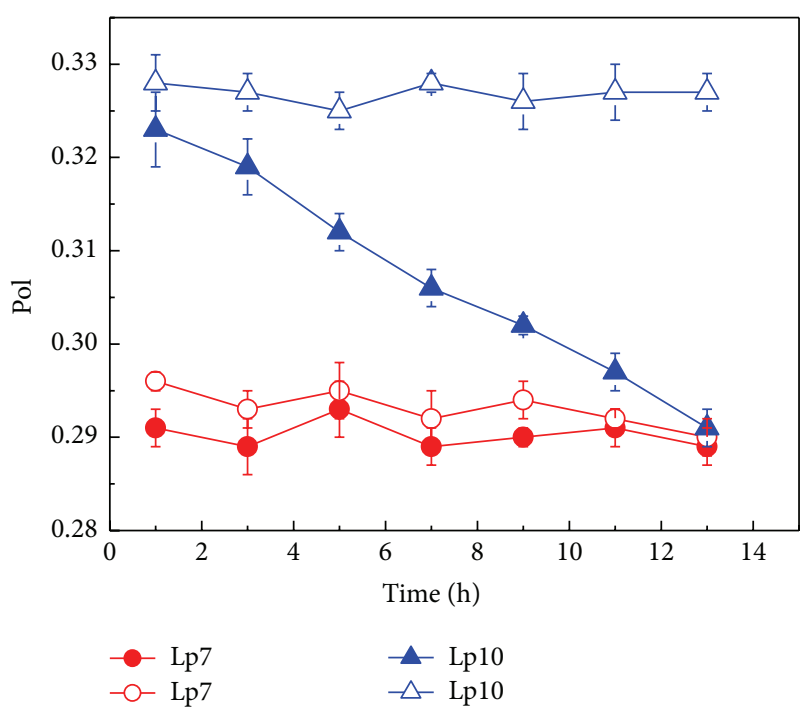

(b)

FIGURE 7: (a) Cumulative release profiles of DOX from liposomes containing DOPC and (b) their polarization measured as a function of time under $\mathrm{pH} 7.4$ and $\mathrm{pH} 6.0$ at $37^{\circ} \mathrm{C}$. Solid symbol: $\mathrm{pH}$ 6.0. Open symbol: $\mathrm{pH}$ 7.4.

be thought that a polymer began to escape from liposomes when the protonation is completed and at that time the quick release could begin. From Figure 4(b), the first $6 \mathrm{~h}$ was mainly a protonation process and after that it was an escaping process. Comparing this with the behaviors of drug release shown in Figure 5, it could be easy to understand that the improvement in release rate of hybrid liposomes is not very significant during the first 5-6 h comparing with that of pure liposome. A quick release step was found to continue till the copolymers have left completely. Copolymers with longer PDPA should require more time to complete the protonation and seemed to give the lipid bilayer more long-time disturbance. The copolymer $\mathrm{mPEG}_{8}-\mathrm{b}-\mathrm{PDPA}_{22}$ was considered a candidate incorporated into liposomes for the next studies.

3.5. Effect of Insertion Ratio on Release. The drug release profiles of liposomes with 0 (Lp1), 2\% (Lp4), 5\% (Lp5), and 10\% (Lp6) copolymer 3 and their liposomal fluorescence polarization were shown in Figure 6. As shown in Figure 6(a), compared with that of Lp1, the Pol values of Lp4-Lp6 increased, where the Lp5 improved most obviously. The PDPA block of the copolymer 3 was thought to be long enough to go across the whole lipid bilayer and then acted as locks in the fluid membrane (as illustrated in Figure 6(b)). Their release profiles were obtained under both $\mathrm{pH}$ values as shown in Figure 6(c). With incorporating copolymers, the drug release rate of hybrid liposomes decreased at $\mathrm{pH}$ 7.4 and increased at $\mathrm{pH}$ 6.0, compared with pure liposome. The results suggested that the insertion of the copolymer significantly enhanced the stability of liposome in neutral condition, while the DOX release was stimulated when exposed to weak acidic environment. For Lp5, it had the most remarkable differences between the two $\mathrm{pH}$ values, and the cumulative release percentage improved from $15.1 \%$ to $53.2 \%$ when $\mathrm{pH}$ decreased from 7.4 to 6.0. However, beyond our expectation, the Lp6, incorporating much more copolymer, did not have the most significant $\mathrm{pH}$-controlled effect on release. Its accumulated release percentages were $18.5 \%$ and $54.7 \%$, respectively. It was thought that too much copolymers inserted into liposomes could impact the spatial structure of vesicle. Here, the DOX leakage at $\mathrm{pH} 7.4$ had somewhat increased, which was consistent with the results of Pol. It was well demonstrated that proper amount of diblock copolymers incorporated into liposome was able to effectively decrease the drug leakage at $\mathrm{pH} 7.4$ and promote the drug release under pH 6.0.

3.6. Effect of Lipid Composition on Release. To our knowledge, the composition of liposome plays an important role in the functions of liposome membrane, such as fluidity or permeability [33]. The above results demonstrated that the maximum release amount of DOX could only reach as high as $55 \%$ even at $\mathrm{pH}$ 6.0. To improve the DOX release efficiency, DOPC, a kind of phospholipids with unsaturated bond, was added to liposome bilayer for adjusting membrane fluidity. Here, HSPC to DOPC at molar ratio of $1: 1$ was selected.

The effect of liposome composition on DOX release was also investigated and shown in Figure 7(a). As shown in Figure 7(a) with increase of PDPA length, the values of accumulated release amount were increased from $63.6 \%$ to $73.8 \%, 81.9 \%$, and $93.4 \%$ at $\mathrm{pH}$ 6.0. The cumulative release amount of liposomes with DOPC significantly improved, in comparison with those of liposomes without DOPC (see Figure 5). In addition, it was easy to find that the drug release profiles of pure liposome with DOPC (Lp7) did almost the same behavior under $\mathrm{pH} 6.0$ and $\mathrm{pH}$ 7.4. Like the results of Lp1 (Figure 5), the accumulated release amounts were 
almost the same, $66.7 \%$ and $63.6 \%$, respectively. Among hybrid liposomes, Lp10 showed the best $\mathrm{pH}$-controlled effect on DOX release, and the difference in release percentage between $\mathrm{pH} 6.0$ and $\mathrm{pH} 7.4$ was about $60 \%$. The maximum amount of DOX release meant almost all cargos had been released into solution at $\mathrm{pH} 6.0$.

It was known that the insertion of DOPC could increase the fluidity of lipid bilayer [22]. Then, the polarization of Lp7 and Lp10 was measured under two $\mathrm{pH}$ values as a function of time. Firstly, as shown in Figure 7(b), the Pol values of Lp7 and Lp10 were lower than those of liposomes without DOPC (as shown in Figure 6(a)). Secondly, the Pol values of Lp7 were almost constant under both $\mathrm{pH}$ values, which was similar to Lp1. For Lp10, its Pol value under pH 7.4 was found to be higher than that of Lp7 and almost did not change over time. When $\mathrm{pH}$ decreased to 6.0, the Pol values of Lp10 reduced rapidly and almost reached the values of Lp7 after 13 h. The Pol results of liposomes seemed to be consistent with the results of DOX release. Compared to the Pol of liposomes with and without DOPC, we could find that the time needed for the recovery of the polarization value to that of pure liposome was not the same, which was $13 \mathrm{~h}$ and $20 \mathrm{~h}$, respectively. It was thought that when the copolymers escaped from liposome, the micropores left on the lipid bilayer and induced a rapid release. The higher fluidity membrane of the liposomes containing DOPC seemed to make the micropores disappear more quickly. This induced different release behaviors of Lp5 and Lp10.

From these results, the DOX release profile could be separated into two steps: rapid and gradual release steps. It was thought that the rapid drug release was dependent on both permeation and diffusion through micropores left by the escaping copolymers. After the copolymers escaped completely, the micropores disappeared due to the fluidity of lipid bilayer. Then, the release began to rely on the membrane permeability resulting in a slow release process. The results showed that the rapid release step of Lp5 and Lp10 needed about $20 \mathrm{~h}$ and $13 \mathrm{~h}$, respectively.

\section{Conclusion}

In summary, diblock copolymers with $\mathrm{pH}$-sensitive PDPA segments synthesized here had a $\mathrm{pH}$ triggering point at about 6.5. The pH-sensitive liposomes were prepared by inserting the copolymers into general liposomes. Diblock copolymers with different chain lengths and molar ratios had different effects on the stability of liposomes. The PDPA segment should be long enough to reach the second layer of the liposome and could act as a lock to fix the bilayer. At pH 7.4, the bilayer fluidity of $\mathrm{pH}$-sensitive liposomes decreased due to the incorporation of copolymers with longer PDPA. Thus, the liposomes inhibited the leakage of DOX in comparison with that of pure liposome. When $\mathrm{pH}$ decreased to 6.0, the release efficiency of DOX had been improved because of copolymer escaping. The membrane property was found to give great impact on the $\mathrm{pH}$-controllability. When DOPC improved membrane fluidity of the liposome, the maximum release amount reached over $90 \%$ and the difference in release amount under two $\mathrm{pH}$ environments increased to be $60 \%$.
The optimization of the lipid compositions provided a superior controlled drug release behavior. These results suggest that liposomes containing $\mathrm{pH}$-sensitive diblock copolymer possess a promising potential application in drug delivery system.

\section{Competing Interests}

The authors declare that they have no competing interests.

\section{Authors' Contributions}

Tian Xia and Weiju Hao equally contributed to this work.

\section{Acknowledgments}

Financial support for this work is provided by the National Natural Science Foundation of China (no. 21276074), the 111 Project of China (no. B08021), and the Fundamental Research Funds for the Central Universities of China.

\section{References}

[1] C.-M. J. Hu and L. F. Zhang, "Nanoparticle-based combination therapy toward overcoming drug resistance in cancer," Biochemical Pharmacology, vol. 83, no. 8, pp. 1104-1111, 2012.

[2] K. M. Galler, L. Aulisa, K. R. Regan, R. N. D’Souza, and J. D. Hartgerink, "Self-assembling multidomain peptide hydrogels: designed susceptibility to enzymatic cleavage allows enhanced cell migration and spreading," Journal of the American Chemical Society, vol. 132, no. 9, pp. 3217-3223, 2010.

[3] Q. Li, Y. Jin, M. Li, and J. Dong, "Drug-loaded star-shaped pHresponsive monomolecular copolymer nanocarriers for tumor targeting and cancer therapy," ACS Biomaterials Science \& Engineering, vol. 1, no. 3, pp. 175-182, 2015.

[4] S. Thamphiwatana, V. Fu, J. Zhu, D. Lu, W. Gao, and L. Zhang, "Nanoparticle-stabilized liposomes for $\mathrm{pH}$-responsive gastric drug delivery," Langmuir, vol. 29, no. 39, pp. 12228-12233, 2013.

[5] Y. Yoshizaki, E. Yuba, N. Sakaguchi, K. Koiwai, A. Harada, and $\mathrm{K}$. Kono, "Potentiation of $\mathrm{pH}$-sensitive polymer-modified liposomes with cationic lipid inclusion as antigen delivery carriers for cancer immunotherapy," Biomaterials, vol. 35, no. 28, pp. 8186-8196, 2014.

[6] H. Aoki, K. Kakinuma, K. Morita et al., "Therapeutic efficacy of targeting chemotherapy using local hyperthermia and thermosensitive liposome: evaluation of drug distribution in a rat glioma model," International Journal of Hyperthermia, vol. 20, no. 6, pp. 595-605, 2004.

[7] K. Kono, T. Murakami, T. Yoshida et al., “Temperature sensitization of liposomes by use of thermosensitive block copolymers synthesized by living cationic polymerization: effect of copolymer chain length," Bioconjugate Chemistry, vol. 16, no. 6, pp. 1367-1374, 2005.

[8] X. Wu, Z. Wang, D. Zhu et al., "PH and thermo dual-stimuliresponsive drug carrier based on mesoporous silica nanoparticles encapsulated in a copolymer-lipid bilayer," ACS Applied Materials \& Interfaces, vol. 5, no. 21, pp. 10895-10903, 2013.

[9] R. Tong, H. D. Hemmati, R. Langer, and D. S. Kohane, "Photoswitchable nanoparticles for triggered tissue penetration 
and drug delivery," Journal of the American Chemical Society, vol. 134, no. 21, pp. 8848-8855, 2012.

[10] Y.-C. Liu, A.-L. M. L. Ny, J. Schmidt, Y. Talmon, B. F. Chmelka, and C. T. Lee Jr., "Photo-assisted gene delivery using lightresponsive catanionic vesicles," Langmuir, vol. 25, no. 10, pp. 5713-5724, 2009.

[11] F. Liu, V. Kozlovskaya, S. Medipelli et al., "Temperaturesensitive polymersomes for controlled delivery of anticancer drugs," Chemistry of Materials, vol. 27, no. 23, pp. 7945-7956, 2015.

[12] J. Fu, Y. Zhu, and Y. Zhao, "Controlled free radical generation against tumor cells by $\mathrm{pH}$-responsive mesoporous silica nanocomposite," Journal of Materials Chemistry B, vol. 2, no. 22, pp. 3538-3548, 2014.

[13] A. Car, P. Baumann, J. T. Duskey, M. Chami, N. Bruns, and W. Meier, "pH-responsive PDMS-b-PDMAEMA micelles for intracellular anticancer drug delivery," Biomacromolecules, vol. 15, no. 9, pp. 3235-3245, 2014.

[14] P. Huang, H. Song, W. Wang et al., "Integrin-targeted zwitterionic polymeric nanoparticles with acid-induced disassembly property for enhanced drug accumulation and release in tumor," Biomacromolecules, vol. 15, no. 8, pp. 3128-3138, 2014.

[15] P. B. Yang and H. Zhang, "Progress in the research of liposome," Journal of Zhejiang Chinese Medical University, vol. 37, pp. 936939, 2013.

[16] D. Q. Zhang and Y. Chen, "Research situation of liposome," Traditional Chinese Medicine and Clinical Pharmacology, vol. 13, pp. 125-128, 2002.

[17] W. J. Hao, X. Han, Y. Z. Shang, S. H. Xu, and H. L. Liu, "Insertion of $\mathrm{pH}$-sensitive bola-type copolymer into liposome as a 'stability anchor' for control of drug release," Colloids and Surfaces B: Biointerfaces, vol. 136, pp. 809-816, 2015.

[18] J. Gaitzsch, I. Canton, D. Appelhans, G. Battaglia, and B. Voit, "Cellular interactions with photo-cross-linked and $\mathrm{pH}-$ sensitive polymersomes: biocompatibility and uptake studies," Biomacromolecules, vol. 13, no. 12, pp. 4188-4195, 2012.

[19] J. C. Zhang, L. L. Wu, F. H. Meng et al., "pH and reduction dualbioresponsive polymersomes for efficient intracellular protein delivery," Langmuir, vol. 28, no. 4, pp. 2056-2065, 2012.

[20] R. T. Pearson, N. J. Warren, A. L. Lewis, S. P. Armes, and G. Battaglia, "Effect of $\mathrm{pH}$ and temperature on PMPC-PDPA copolymer self-assembly," Macromolecules, vol. 46, no. 4, pp. 1400-1407, 2013.

[21] H. Yu, Z. Xu, D. Wang et al., "Intracellular pH-activated PEGb-PDPA wormlike micelles for hydrophobic drug delivery," Polymer Chemistry, vol. 4, no. 19, pp. 5052-5055, 2013.

[22] K. Suga and H. Umakoshi, "Detection of nanosized ordered domains in DOPC/DPPC and DOPC/CH binary lipid mixture systems of large unilamellar vesicles using a TEMPO quenching method," Langmuir, vol. 29, no. 15, pp. 4830-4838, 2013.

[23] N. Ehrlich, A. L. Christensen, and D. Stamou, "Fluorescence anisotropy based single liposome assay to measure moleculemembrane interactions," Analytical Chemistry, vol. 83, no. 21, pp. 8169-8176, 2011.

[24] Y. Niu, X. Wang, S. Chai, Z. Chen, X. An, and W. Shen, "Effects of curcumin concentration and temperature on the spectroscopic properties of liposomal curcumin," Journal of Agricultural and Food Chemistry, vol. 60, no. 7, pp. 1865-1870, 2012.

[25] J. Qian and C. Berkland, "pH-sensitive triblock copolymers for efficient siRNA encapsulation and delivery," Polymer Chemistry, vol. 6, no. 18, pp. 3472-3479, 2015.
[26] J. Du, L. Fan, and Q. Liu, "pH-Sensitive block copolymer vesicles with variable trigger points for drug delivery," Macromolecules, vol. 45, no. 20, pp. 8275-8283, 2012.

[27] S. V. Lale, A. Aravind, D. S. Kumar, and V. Koul, "AS1411 aptamer and folic acid functionalized $\mathrm{pH}$-responsive ATRP fabricated pPEGMA-PCL-pPEGMA polymeric nanoparticles for targeted drug delivery in cancer therapy," Biomacromolecules, vol. 15, no. 5, pp. 1737-1752, 2014.

[28] X. M. Mu and S. Q. Liang, "Preparation method of liposome and its research progress," Lishizhen Medicine and Materia Medica Research, vol. 19, pp. 1784-1786, 2008.

[29] S. H. Chen, G. Y. Liu, and Y. C. Wei, "Research progress in determination method of encapsulation efficiency of liposome," PLA Pharmaceutical Journal, vol. 27, pp. 79-82, 2011.

[30] H. Yu, Y. Zou, Y. Wang et al., "Overcoming endosomal barrier by amphotericin B-Loaded dual pH-responsive PDMA-b-PDPA micelleplexes for siRNA delivery," Nano Letters, vol. 5, pp. 92469255, 2011.

[31] E. A. Kotova, A. V. Kuzevanov, A. A. Pashkovskaya, and Y. N. Antonenko, "Selective permeabilization of lipid membranes by photodynamic action via formation of hydrophobic defects or pre-pores," Biochimica et Biophysica Acta (BBA) Biomembranes, vol. 1808, no. 9, pp. 2252-2257, 2011.

[32] E. G. Randles and P. R. Bergethon, "A photodependent switch of liposome stability and permeability," Langmuir, vol. 29, no. 5, pp. 1490-1497, 2013.

[33] A. Garu, G. Moku, S. K. Gulla et al., "Examples of tumor growth inhibition properties of liposomal formulations of $\mathrm{pH}$-sensitive histidinylated cationic amphiphiles," ACS Biomaterials Science \& Engineering, vol. 1, no. 8, pp. 646-655, 2015. 

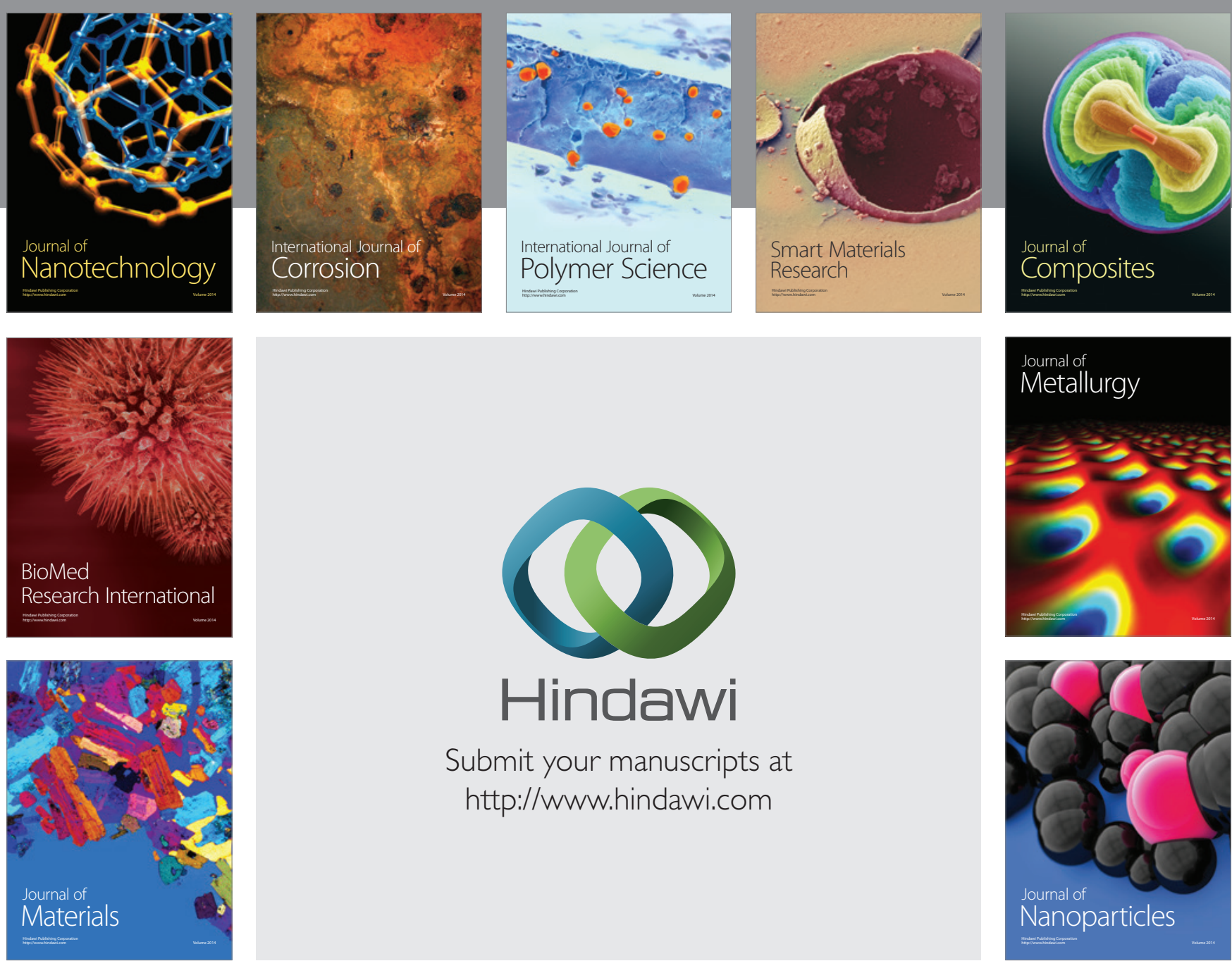

\section{Hindawi}

Submit your manuscripts at

http://www.hindawi.com

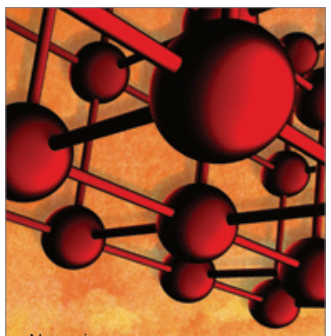

Materials Science and Engineering
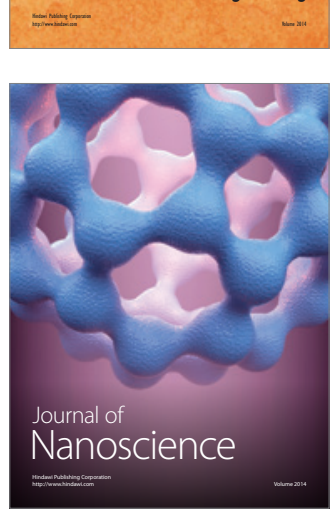
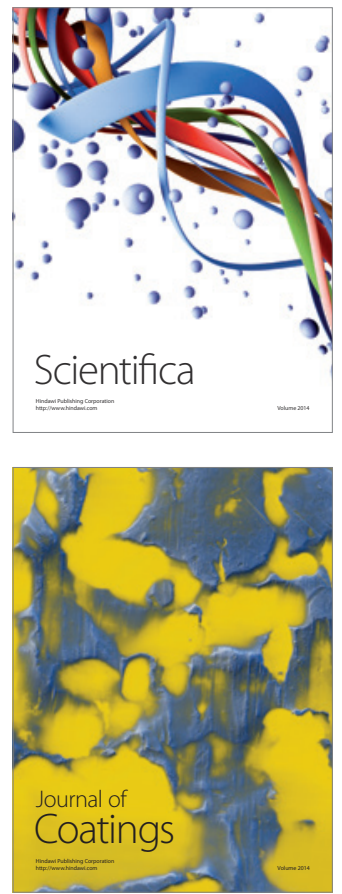
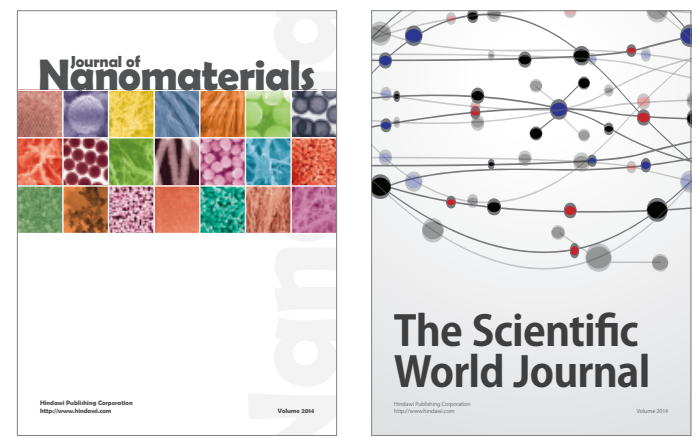

The Scientific World Journal
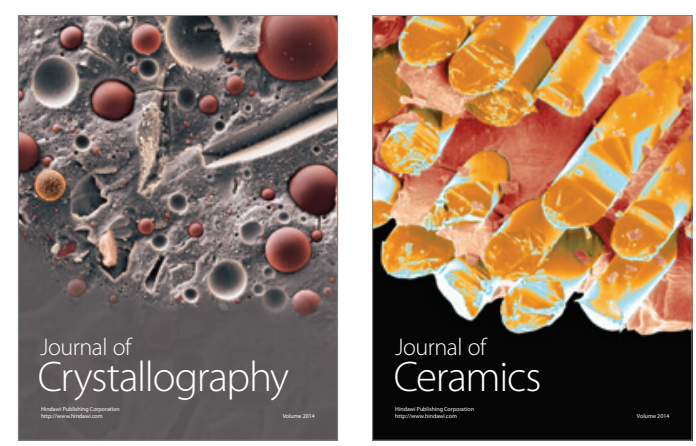
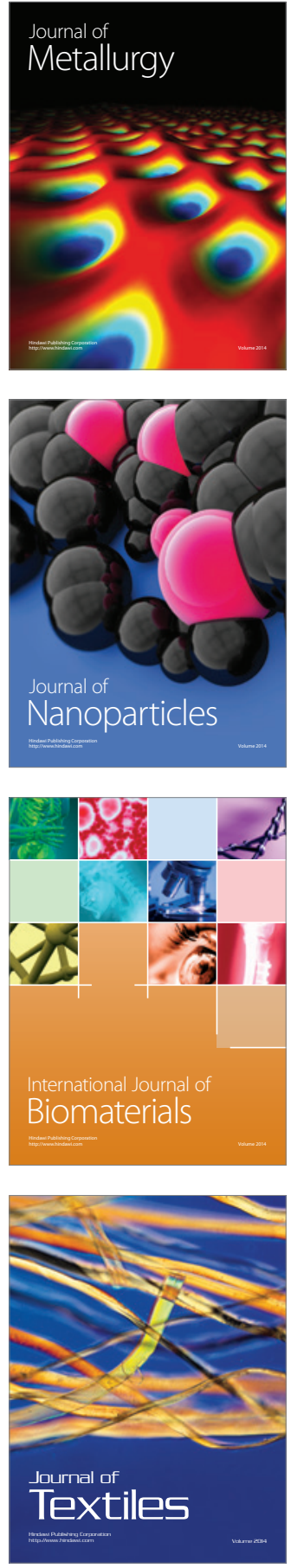